\title{
Chapter 8 \\ Studying the Impact of Human \\ Resources on the Efficiency of Healthcare Systems and Person-Centred Care
}

\author{
Bojana Knezevic, Roman Andrzej Lewandowski, Anatoliy Goncharuk, \\ and Maja Vajagic
}

\begin{abstract}
We explore the alternative explanation for barriers and facilitators for implementation of PCC evolving from human resources through the lenses of institutional theory. We have deepened the explanation by adding the perspective of different institutional logics, which shows that the physician's resistance or nurses' support may originate from the differences in institutional logics. Working with patients by applying person-centered principles places new demands on health professionals. It is widely agreed that education and training are very important for the clarification on the roles of professionals in the person-centred care. PCC education programs were designed to be delivered through informal training, continued medical education, leadership development and training through mentors' system. Managers, on the other hand, may support the implementation of PCC, but their motivation may be less oriented to increase of service quality, than gaining higher external legitimacy of the organization and increase organizational access to external resources. Therefore, managers may not implement sufficient control and motivational mechanisms for healthcare professionals for following PCC routines and make them slip back into 'usual care' or lose interest, knowledge or commitment. As the psychological state of medical staff can determine the duration and success of the treatment and care,
\end{abstract}

\footnotetext{
B. Knezevic ( $\varangle)$

University Hospital Centre Zagreb, Zagreb, Croatia

e-mail: bojana.knezevic@kbc-zagreb.hr
}

R. A. Lewandowski

Institute of Management and Quality Science, Faculty of Economics, University of Warmia and Mazury, 10-720 Olsztyn, Poland

e-mail: rlewando@wp.pl

A. Goncharuk

International Humanitarian University, Odessa, Ukraine

e-mail:agg@ua.fm

M. Vajagic

Croatian Health Insurance Fund, Zagreb, Croatia

e-mail: maja.vajagic@hzzo.hr

R. A. Lewandowski

Voivodeship Re-Habilitation Hospital for Children in Ameryka, Olsztynek, Poland

(C) The Author(s) 2022

D. Kriksciuniene and V. Sakalauskas (eds.), Intelligent Systems for Sustainable

Person-Centered Healthcare, Intelligent Systems Reference Library 205,

https://doi.org/10.1007/978-3-030-79353-1_8 
therefore they should be properly motivated. In this chapter we show comparative research study in Ukraine and Poland. The methodology of this study selected a list of motivators for medical staff in both countries. The results of this study brought the main findings that may be useful for reforming inefficient healthcare systems.

Keywords Human resources $\cdot$ PCC education · Hospital managers · Institutional theory $\cdot$ Motivation in healthcare

\subsection{Introduction}

Human resources in health care system are the different kinds of clinical and non-clinical staff responsible for public and individual health intervention. Human resources are one of the most important inputs leading to the efficient output of health care system [39]. In addition to doctors and nurses, there are many other professionals involved in treatment and care processes, such as psychologists, laboratory staff, pharmacists, dietitians, and others. For many centuries health care was managed by medical professionals, however, rising costs of health care services forced governments' to impose tighter controls over the medical practice by the implementation of New Public Management (NPM) reform. As a result, professional managers with their business-like logic has been introduced in medical settings previously dominated by medics with their professional, care logic [45]. However, the implementation of NPM together with managers has not restrained the increase of expenditure for medical services and safeguard quality improvement [41]. Thus, a new way of cost containment and quality improvement has to be found.

The problem is extremely important since in the near future the European healthcare systems could be financially unsustainable and fail to protect the current level of access and quality of medical services. The main problems are demographic changes as the aging population has resulted in people living longer, but also a growing prevalence of chronic long-standing illnesses [77]. The rising number of people with complex care needs requires the development of care systems that bring together a range of professionals and skills from the healthcare, long term and social care sectors [24]. Long-term diseases are today the leading cause of mortality worldwide and are estimated to be the leading cause of disability [23]. In this context quality improvement in healthcare should consist of systematic and continuous actions that lead to a measurable enhancement in healthcare services [36]. The most important goals for improvement in healthcare are safe, effective, patient-centred, timely, efficient, and equitable healthcare [37]. The quality improvement and cost containment are challenging since the healthcare sector is highly fragmented, organized along with different subsectors, disciplines and diseases [13].

Recently, promising results concerning quality improvements and cost containments have been achieved by implementing Person-Centred Care (PCC) in medical services (Fors et al. 2017). Person-centred care is today widely advocated as a key component of effective illness management. PCC has been shown to advance the 
match between a provider of care and patient on treatment plans, improve health outcomes and increase patient satisfaction [23]. PCC is a way of thinking and doing things that sees the people using health and social services as equal partners in planning, developing and monitoring care to make sure it meets their needs. This means putting people and their families at the centre of decisions and seeing them as experts, working alongside professionals to get the best outcome [59].

From the research appears, however, that many implementations of PCC are difficult to become sustainable [4]. Early research has recognized that the whole context of the care environment and system of education could be the source of potential barriers $[51,66]$. Studies looking in more detail in the care context identified that professional practice, beliefs and cultures are the most prominent obstacles [8]. More recent research, to some extent, confirmed previously identified barriers and defined them as: traditional practices and structures, skeptical, stereotypical attitudes from professionals; and factors related to the development of person-centred interventions [56]. Moore et al. [56] also identify facilitators for PCC implementation, which are closely related to the barriers. They claim that organizational factors, professionals' attitude, leadership and training as well as the way PCC was delivered across projects may facilitate its implementation. Although McCormack [8], Bolster and Manias [51] and Moore et al. [56] identified barriers and facilitators for the implementation and functioning of PCC, they have not clearly explained what mechanisms make these barriers and facilitators arise. Thus in this chapter, we tried to fill this scientific gap by looking at these barriers and facilitators from the institutional theory point of view.

Although initial studies indicate the positive influence of PCC on quality improvement and cost containment (Fors et al. 2017), the results to some extent may be biased. In the literature analyzing PCC implementation [56, 75] authors have recognized important problems but have not explained their sources. In our opinion, these problems may be the symptoms of structural issues concerning such phenomena as institutional decoupling, rivalry between different medical professionals such as nurses and physicians as well as coexistence of various institutional logics such as professional logic and managerial logic [44]. Problems recognized by Moore et al. [56] and Naldemirci et al. [58] may also originate from the fact that PCC to some extent could function as a "powerful myth" [54], this means that PCC could not be implemented in order to increase quality and contain costs but to gaining external social legitimacy. In this chapter, we have not intended to say that PCC does not work. But the inference about the above mentioned structural problems and recognition that PCC may be implemented as a myth may have far-reaching consequences. The most important corollaries may include unrealistic perception of PCC effects, the extent to which PCC is recommended for various treatment and care interventions, and how human resource management should be organized during PCC implementation and functioning. In this chapter, we deepen the understanding of the role of healthcare and its institutional logics in the context of PCC implementation. We also describe the role of the motivation of healthcare workers in the process of changing their way of thinking. 


\subsection{Person-Centred Care in the Context of Human Resource Management in Healthcare}

In everyday reality and practice, disease-focused and clinician centred care are emphasized treating a disease, without attention to the needs of the patient, and centred on the health professional as the sole source of control. Working with patients in a more person-centred manner places new demands on health professionals [66]. Person-centred care means treating patients as individuals and as equal partners in the process of healing. Person-centred care supports people to develop the knowledge, skills and confidence they need to make informed decisions about their own health [35]. It is not a medical model and should be regarded as a multidisciplinary approach, recognizing that a person may need more than one professional to support them. The multidisciplinary approach in hospitals is most often dominated by medical professionals [36]. Health care professionals who are involved in the healing process could be consist of doctors, nurses, psychologists, social workers, pharmacists, dietitians, managers in healthcare and others. Most people want to help themselves, so the health system should be able to ensure that they acquire the knowledge, skills and confidence to do in this way [15] Working in the way of person-centred care means recognizing people's capabilities and potential to manage and improve their own health, not seeing them simply passive recipients of care or as victims of the disease. Professionals often underestimate the extent to which patients are able to take responsibility for their health. Many patients would be willing and indeed eager to do so if their capabilities were recognized, supported and strengthened [15]. For those people who are with limited or without the mental capacity to assume greater responsibility for their care, the system should ensure family, relatives, home caregivers and trained advocates who have to be fully involved in the care planning process.

Person-centred care (PCC) is a new way of thinking and doing things that see people using health and social services as equal partners. Patients, medical professionals and healthcare managers, as well as policymakers should work together and develop structures to measure and monitor PCC performance and to promote PCC practice for suitable interventions [66]. As well, PCC has to be monitored based on feedback from patients since they should be the ultimate reviewer of the efficiency of PCC functioning. Objective measurement of whether PCC brings quality improvement and cost containment (see Chap. 3) is extremely important since as we have proved further - the implementation and functioning of PCC could be distorted. Mostly due to complex and multiparadigmatic human resource relationships.

\subsection{Studying the Human Resources Impact on PCC}

From the human resource and the organizational theory perspective, organizations are the collection of individuals that could be structured according to many criteria, 
for example, as members of the organizational unit, specific professional group and also different informal social networks existing within an organization. However, from the institutional theory, we could perceive human resources as a collection of organizational actors with different organizational logics decoupling their "usual practices" ensuring organizational effectiveness from ceremonial conformity with externally legitimate rules.

In order to explain causes and sources of barriers to PCC implementation and functioning we did not perform our own field research, instead, we based our inference on previous studies that tried to explain Alharbi et al. [4], Moore et al. [56] and Naldemirci et al. [58] observations in more detail and from the institutional theory perspective.

\subsubsection{PCC Implementation as External Pressure}

Naldemirci et al. [58], based on normalization process theory (NPT) [50] tried to discover the way organizations implement PCC. They revealed that organizations use two strategies to implement PCC: deliberate and emergent. They claimed that deliberate strategies consist of training, seminars and financing, and proved to be necessary and effective in disseminating the knowledge about PCC but were not sufficient to guarantee positive implementation outcomes. Emergent strategies, involved informal meetings, discussing real situations, 'reflecting on action' and 'learning in action'. Although the authors used the label of "emergent strategies" we do not find evidence in the research about the pure bottom-up initiative [58]. As in the literature, there is no clear cut-off between deliberate and emergent strategies we accept the label "emergent strategies" in the sense that "the central leadership intentionally creates the conditions under which strategies can emerge" [55]. This entitles us to the conclusion that PCC implementations as describe them Moore et al. [56] and Naldemirci et al. [58] took place rather by outside pressure than through bottom-up processes leading by professionals working directly with patients. Therefore, all analyses described further in the chapter were conducted under the assumption that the implementation of PCC was initiated by the constituency external to the organization (scientific project, local government programs) or external, at least, to the professionals working directly with patients (managerial initiatives). To clarify our scientific argument we adopt a simplification that the purpose of PCC implementation is to change the 'usual care' practices into PCC routines.

\subsubsection{PCC as a Powerful Myth}

Although there is evidence that PCC is an effective tool for quality improvement and cost containment (e.g., Fors et al. 2017), and gained significant public support especially in Sweden, for example, through government funding of the GPCC, it could 
not be treated as a universal solution. It means that in some settings externally driven PCC implementation may not much to the clinical demands and type of patients. The lack of fit of PCC routines to performed medical services in the organization could not be recognized as a definite premise against PCC implementation but rather as some barriers that must be overcome. If the PCC would be implemented in bottomup processes by professionals directly working with patients, then the fit of PCC routines to clinical demands and type of patients would be highly probable.

However, in externally driven implementation, explained in the previous section, the degree of fit is unknown. Then, the fit could range from the perfect fit to the misfit. But it might be difficult to recognize in advance, before the implementation, at what point of the continuum clinical demands and type of patients, treated in a medical organization are located. The recognition of the fit is problematic since in externally driven PCC implementation the initial resistance to this change cannot be treated as the objective sign of the misfit. Thus, it is unknown to what extent the pressure should be executed to overcome the barriers to the PCC implementation. Where is the point when the training and experience gained by the time of implementation convince health workers and PCC routines will be normalized, what means "it becomes routinely embedded in the matrices of already existing, socially patterned, knowledge and practices" [50].

Even though it might be visible before the implementation that PCC routines do not fit certain clinical demands and types of patients in an organization, reviling this by professionals and managers from the organization may be difficult. The more PCC had gained recognition and support from political bodies there would be higher social pressure to implement PCC in every medical organization. PCC has already being promoted by many scholars and powerful organizations, such as WHO and the European Committee for Standardization (CEN) $)^{1}$ as a "taken-for-granted solution" capable of improving quality and contain costs in almost every medical organization. Such kind of external legitimacy has a high potential to establish PCC as an institutional rule (norm) thus, enforce institutional isomorphism [20]. In this context, PCC could be also perceived by many organizations as a "powerful myth" in a sense this notion is described in the seminal work of [54].

\subsubsection{Implications for PCC Implementation as a Powerful Myth}

The inference that PCC could be perceived as an institutional rule functioning as a powerful myth has many important implications and allow shedding new light on the barriers of implementation of PCC reviled in previous studies. In this environment, a ceremonial adaptation of PCC would be the natural reaction to protect the efficiency

\footnotetext{
${ }^{1}$ CEN published The European Standard EN 17,398:2020, "Patient involvement in health careMinimum requirements for person-centred care" (https://iteh.fr/catalog/tc/cen/bc1d2237-3a9046e8-a976-89c0ae53c7cc/cen-tc-450).
} 
of "usual care" against the external implementation of new routines. From the literature, we know that to resolve the conflict between ceremonial rules and efficiency organizations call for decoupling [54]. Decupling means that under external pressure an organization creates two worlds. The one visible from the outside, consisting of symbolic activity acceptable by external constituencies and therefore giving an organization legitimacy and access to resources. And the second, internal, following "usual" practices that allow the organization to render efficiently their day-to-day work [45].

Decoupling may have a tremendous influence on researchers' inference investigating the results of PCC implementation. Scholars, unaware of the possibility of decoupling, may perceive ceremonial conformity decoupled from everyday practices only as some minor lack of adherence to PCC routines instead of deep institutional problems. For example, scientists revealing that "Several researchers described working with professionals who said they were practicing PCC when they were not." Moore et al. [56] should dig further into the field research to discover whether the PCC routines were followed only as a ceremonial activity to "show off" in front of the external spectator (e.g., the scientist) or it was only "conflicting and/or divergent views about PCC and the difficulty of translating abstract principles into concrete practices." $[58,56]$. In this situation, the difference between interpretations of the results of the investigation could be totally opposite. In the first case, a researcher should conclude that the PCC was not implemented successfully and probably it would be difficult to find any solution to improve the results of the implementation. In the second case, a scholar could assume that the implementation was quite successful, only some employees need more training, motivation and experience with PCC.

The decoupling, however, could be deeply embedded and during the research may not be discovered. Thus, a researcher needs more premises to interpret some lack of compliance with PCC routines as a "ceremonial implementation". From the literature we know, that organizations with easily measured outcomes and high potential to prove objectively their contribution to the society (e.g. surgical wards) may resist openly the implementation of PCC and do not need to go into ceremonial activities [54]. As an example, we can bring Moore et al. [56] study in which they reported that "The surgical setting proved a particularly tough climate for PCC because of high patient turnover and standardized prescribing". Hence, in this case, a researcher could be more certain about the results of their investigation knowing that organizational actors were more honest.

Organizations providing services that are difficult to assess are more willing to incorporate institutionalized rules bringing external trust and confidence to their outputs [54]. Therefore, the decision about the implementation of PCC could be perceived with higher suspicion as an attempt to increase organizational legitimacy. These types of organizations in order to expand their survival prospects may implement PCC regardless of sharp conflict with current efficiency criteria and well-suited practices and procedures. Scholars studying these organizations should take into consideration the potential ceremonial implementation of PCC. 


\subsubsection{Institutional Logics}

Building on the above discussion we can further deepen our understanding of causes and sources of implementation barriers of PCC through using another perspectiveinstitutional logics. From the perspective of institutional theory, day-to-day practices of organizational actors are the result of institutional logics existing in an organization since institutional logics are "socially constructed, historical patterns of material practices, assumptions, values, beliefs and rules" [74], “...the basis of taken-forgranted rules" ([62], p. 629) and "frames of reference that condition actors' choices for sense-making, the vocabulary they use to motivate action, and their sense of self and identity" [76]. Institutional logics deliver a belief system and associated practices and are the organizing principles that shape cognition and behavior [47, 62, $67,71,75]$. An organization is characterized by institutional complexity, embracing multiple logics, as opposed to being dominated by a single logic. These different logics influence organizational strategy, structure and especially day-to-day practices [32].

These multiple logics may cohabitate in different configurations, they could be competitive, co-operative, orthogonal or blurred [30]. However, relationships between logics might be subject to interpretation by individual organizational actors as they can execute some degree of agency and selectively employ, interpret, and enact logics or some parts of them $[38,53]$. The coexistence of multiple logics is especially complex in organizations with high interdependency, as in healthcare, where at least three main logics cohabitate: physicians institutional logic with core value focusing on the diagnosis, inference and treatment [1], nurses institutional logic concentrating on care and managers logic with core values relating to economic and business issues. These logics do not differ only in values, rules and practices but they also vary in hierarchical relationships and realms of responsibility.

\subsubsection{Influence of Nurses and Physicians Institutional Logics on PCC Implementation}

Physicians, for example, always have exercised a high degree of autonomy and clinical judgment, remain relatively free from external regulations and reluctantly transfer their core work to other professions, using an arsenal of methods to defend their territory $[1,25,26]$. Nurses on the other hand align with more holistic care for the patient compared to physicians [17]. "The role of nursing [...] is to care and that of a doctor is to cure." [52]. The situation of nurses is also significantly different in terms of hierarchical relationships in the workplace. Although nursing during the last decades went through a process of professionalization, changed the status from personnel rendering simple auxiliary functions under direct physicians' supervision to professionals offered medical advice [72] is still perceived as inferior to physicians [52]. Managers, in a sense of top organizational leaders, exercise the 
highest freedom and driving force in medical settings. In contrast to the previous two professions, managers values and area of activity, focuses not on patients but on the whole organization. Taking into account the above discrepancies between institutional logics, it is unlikely that these three intuitional logics may respond similarly to the implementation of PCC.

From Alharbi et al. [4], Moore et al. [56] and Naldemirci et al. [58] studies appear that doctors, resisted the implementation of PCC, while nurses were much more supportive of implementing these new practices. This difference could be explained by two causes. The first explanation relates to hierarchical interdependence. Physicians, as was mentioned earlier, have had always high status and superior position, and were not interested in any change. These cannot be said about nurses. Nurses, therefore, had seen the change, the implementation of PCC as an opportunity to improve their position in the organizational hierarchy. They expressed this in the interview: "In person-centered care nurses get a new role, actually, in the team, because we have our individual task to perform (...). But we have a different role and we need to work together with the physician, not under the physician" $[56,75]$. Nurses, and other "auxiliary" professionals support for organizational change such as PCC implementation is not unique. A similar situation was observed, for example, during the healthcare reform in Canada. There, registered nurses and physiotherapists supported the change since they realized that the new system 'could result in a higher profile for their profession' [63].

The second explanation relates to the significance and visibility of input each profession delivers to the final output of the medical organization. Professions similarly to organizations have to prove their effectiveness and value of contributions to the outcome to maintain or improve their external legitimization in the society [26]. Physicians with their well-defined tasks consisting of diagnosis, inference and treatment [1] did not feel the need to change their practice to gain more legitimacy from PCC implementation, which might be perceived by researchers as resistance. Nurses, on the other hand, performing in many situations auxiliary tasks, again could see the implementation of PCC as an opportunity for gaining more external legitimization as an independent profession.

\subsubsection{Managers Institutional Logic Influence on PCC Implementation}

Since the 1980s, after the introduction of the New Public Management (NPM) paradigm to health care systems, managers have started to play important role in medical organizations. As a result, additional managerial logic has been introduced to organizations earlier dominated by professional logics [44]. Thus, in medical settings managers have become another factor that had to be taken into account during the implementation of any important change, such as the implementation of 
PCC. Managerial role in the PCC implementation has been also acknowledged by previous research:

"Another barrier was the inter-professional hierarchy between doctors and nurses. The implementation of this framework depended upon better cooperation between different professional groups. However many early adopters came from the nursing profession and some doctors were not initially keen to embrace the model. Existing hierarchies posed problems for the collective action and support of managers was required" [58].

The excerpt from the interview has shown that managers played a facilitating role in the implementation process. Managers also support the implementation of PCC, for example by devoting resources in the form of relieving some nurses from their duties to became PCC "ambassadors" [58]. But the managerial motivation to implement PCC might be different than those of nurses. Nurses may perceive practices related to PCC as the vehicle supporting their claims to higher organizational and professional positions, hence they were eagerly rendering PCC routines. Managers responsible for ensuring organizational access to external resources might be rater motivated by the increase of external legitimacy of the organization.

Some studies raise the issue that PCC is more time and resource consuming than "usual care" and lower organizational productivity which may lead to a decrease of efficiency (e.g.: $[4,75$. It did not mean that PCC failed in cost containment but the savings may be not within an organization but outside - other parts of the healthcare system. This is the case when PCC leads to reduced "time of hospitalization" [58]. But the reduced time of hospitalization, may increase patients' turnover and consequently workload for the ward staff and consumption of hospital resources. Such a situation should discourage managers from PCC implementation. Since from the literature, we know that in some hospitals, managers use even ethically questionable methods to increase efficiency. For example, some managers use case-mix (DRG) tariffs to screen patients and push pressure on physicians to admit only those patients who are "profitable" $[14,43]$ and use specialist software which advises, and also controls physicians whether they apply optimal lengths of stay and proper medical procedures to patients concerning their conditions (diagnostic codes) to maximize revenues from the payer [65]. Taking into account potentially contradictory managerial activities, on the one side supporting the implementation of PCC which could lower organizational economic efficiency and on the other side, strong actions to increase the economic efficiency-deeper analysis is needed. The problem with the perception of PCC as a "powerful myth" is that managers to increase legitimacy not only conform to myths but also maintain the appearance that the myths actually work [54].

This contradiction can be explained in terms of institutional theory. As it was already mentioned above, managers may resolve the contradictory activities by decoupling, in other words, separating employees' internal day-to-day activities from the externally visible routines. This would mean that the implementation of PCC could be to some extent ceremonial, especially in areas where the resources are the most expensive. Ceremonial implementation of PCC could be explained by two phenomena observed by Alharbi et al. [4], Moore et al. [56] and Naldemirci et al. [58]. First, during the field study, the scholars observed "professionals who said they 
were practicing PCC when they were not." [56] and most of them were physicians [58] who are the most expensive part of human resources. Second, that researchers after returning to the medical setting some time after the implementation observed a significant rate of abandonment of PCC routines [4]. The abandonment could mean that organizations after gaining external visibility as PCC-practicing, slept back to their "usual care".

In the above sections, we explain, based on institutional theory, some causes and sources of barriers created by human resources. Further, we describe facilitators supporting PCC implementation.

\subsection{Education and Training Programs in PCC}

International experts agree that education and training are very important for the clarification on the roles of professionals in person-centred care. With the evolution of PCC, there is a need for innovative education programs that are endorsed by key stakeholders, including medical faculty, administrative directors and accrediting bodies. Educational programs should also include administrative staff, volunteers and other professionals involved in care, who are needed to support the cultural change. As integrating PCC into the health care curriculum does not directly lead to implementation into practice, PCC education programs should be designed to continue through informal training, continued medical education, continued leadership development and training through mentors system [66

Healthcare workers who choose to work in person-centred care places new demands on them. Current education tends to focus on the biomedical model, and it is not developed with patients and all health-care providers. Future models of education incorporate both perspectives in the development of training. It requires some specific skills as excellent listening, communication and negotiation skills and the capacity to respond flexibly to people's individual needs [66, 15].

Institute of Medicine (IOM) conclude two decades before that all health professionals should be educated to deliver patient-centred care as members of an interdisciplinary team, emphasizing evidence-based practice, quality improvement approaches, and informatics [37].

Modified the conclusion of IOM, the most important topics in PPC education and training are:

- Provide person-centred care-identify, respect, and care about patients as a person. Recognize every person (professionals and private persons) who take care of ill person. Take into a count personal difference, values, preferences, and expressed needs; relieve pain and suffering; coordinate continuous care; listen to, clearly inform, communicate with, and educate patients; share decision-making and management; and continuously advocate disease prevention, wellness, and promotion of healthy lifestyles. 
- Work in interdisciplinary teams - cooperate, collaborate, communicate, and integrate care in teams to ensure that care is continuous and reliable. Different means of experts and settings for delivering care, such as managed care, community-based care, rehabilitation centres, and critical pathway systems, require interdisciplinary teams to provide the necessary coordination.

- Evidence-based-medicine - integrates the best research with clinical expertise and patient values for optimum care, and participates in learning and research activities to the extent feasible.

- Quality improvement in healthcare-identify risk in care; understand and implement basic safety design principles, such as standardization and simplification; continually understand and measure the quality of care in terms of structure, process, and outcomes in relation to patient and community needs; and design and test interventions to change processes and systems of care, with the objective of improving quality.

- Use new technologies and informatics - use of telemedicine, Web-based communication channels, using patients preferred communication channels, manage knowledge, mitigate error, and support decision making using information technology.

Effective evidence-based medicine is central to what most patients need, but personcentred care cannot be reduced to guidelines. Guidelines and protocols are important, but they must not exclude the important human qualities of caring and compassion, which are highly valued by patients Human resources in health sector changes also seek to improve the quality of services and patients' satisfaction.

At the organization level, management and payment systems should encourage healthcare providers to espouse the values of people-centred care. Clinical governance and other quality improvement initiatives can be established to monitor and improve provider behavior [34].

The health care financing system which largely does not reimburse professionals for time spent coordinating and integrating care or providing care through alternative vehicles, such as over the Internet or via telephone-further constrains clinicians' efforts to care for patients [37].

Quality improvement leaders in hospitals need to be included in the development of these programs through the measure for improving the quality of the work process. One of the barriers to PCC implementation in healthcare is the result of the lack of emphasis on PCC in medical education. The lack of understanding of person-centred care concept could lead to a lack of motivation for implementation [66].

\subsection{Study of Health Professionals' Motivation and Efficiency of Healthcare Systems}

We rarely think about how our health is not so much in our own hands but it is in the hands of the medical staff that treats and cares for us. Respectively, it is obscure to 
contemplate the difficulties these people face in terms of mood, workplace stress and satisfaction with their careers as well as overall lives-especially in a time of need. The psychological state of medical staff, thus, can determine the duration and success of the treatment. To improve this state - by making it adequate and positive-doctors, nurses and other health professionals should be properly motivated, i.e., induced for high efficiency and quality of work.

Obviously, the healthcare systems, in which medical staff is properly motivated, show a higher level of effectiveness and efficiency and, vice versa, improperly motivated a lower level [3, 21, 61, 64, 70, 73]. Recent research on healthcare performance in Europe applied data envelopment analysis and revealed countries with high and low effectiveness and efficiency rates continent-wide [46]. Generally, healthcare effectiveness is measured as the ratio of healthy years lived and life expectancy per infant mortality [3, 70, 73]. However, according to Lo Storto and Goncharuk's approach [46], the effectiveness of the healthcare system is based solely on the quality of care. Besides, the healthcare efficiency reflects how many medical doctors, nurses, and other health professionals in correlation with available beds in hospitals are needed to meet the demand for healthcare services among the population of a country. They stated the higher the number of medical staff and hospital beds versus demand interlinked with an overall higher level of healthcare efficiency. Moreover, during the period from 2011 to 2014, only three countries remained continuously the most efficient healthcare systems in Europe, namely, Ireland, Portugal and Poland. It should be stressed, however, that Sweden jumped by almost $50 \%$ and became relatively effective in 2014 [46].

Recently Del Rocío Moreno-Enguix et al. [18] also identified the leading countries across the continent and found the United Kingdom, Cyprus and Poland as the most efficient. Moreover, other prominent studies have rated the Polish system as the highest efficient healthcare system in Europe [9, 27, 42]. Utilizing this standpoint, Poland remains the best country to assess healthcare efficiency with different approaches to efficiency assessment [10]-leading us to look deeper into its experience in terms of medical staff motivation. As such, learning about how and what motivates Polish medical staff to show high efficiency underscores an important premise in a medical and European context.

On the other side, Lo Storto and Goncharuk [46] showed that the healthcare system of Ukraine was the least efficient among 33 European countries. Goncharuk [28] studied the motivation of Ukrainian medical staff in terms of essential features from an external and internal perspective, including different motivators for various groups of medical staff (i.e., profession, gender and age) as well as significant disparities between Ukrainian health professionals and their colleagues from other countries. These differences may explain the performance of Ukrainian medical staff and the inefficiency of its healthcare system.

As a result, Goncharuk et al. [29] assumed the behaviour and motivation of medical staff in a low-performing healthcare system (i.e. Ukraine) is fundamentally different from an efficient one (i.e. Poland). The authors have compiled research to test comparative findings for different motivators of medical staff in countries with a high gap in 
healthcare efficiency by examining the motivation of health professionals in Polish and two Ukrainian hospitals.

Despite the motivators and incentives necessary for improving employee performance and organisational effectiveness [2, 11, 22, 48, 49, 57, 60, 68], we have not found in-depth studies on the relationship between medical staff motivation and healthcare efficiency (i.e. at the national level). So we fulfilled this gap by testing different motivators for medical staff in countries with a high gap in healthcare efficiency.

The methodology of this study selected a list of motivators for medical staff in countries with a high gap in healthcare efficiency-Polish, i.e., considered efficient and Ukrainian, i.e. considered inefficient. The study tested the following null hypothesis H0: there is not a significant difference between the motivators for medical staff of the two countries with a high gap in healthcare performance. So, in the event that $\mathrm{HO}$ is true, we state that the motivation of medical staff has not a significant relationship with the efficiency of the healthcare system. We used a null hypothesis significance test to verify the zero difference [69]. The study employed the following six-stage scheme illustrated in Fig. 8.1.

In this study, we utilised the "Evaluation of motivators questionnaire for medical staff" adapted from Goncharuk's [28] groundwork on assessing medical staff incentives in Ukraine. A twenty-six-question questionnaire was put together using a Likert scale (i.e., 1-very unsatisfied, 2-unsatisfied, 3-neutral, 4-satisfied and 5-very satisfied) and pilot tested with medical staff of Odessa hospitals in Ukraine in the last quarter of 2018.

After a thorough fine-tuning of the questionnaire, the hospitals in Poland as well as in Ukraine agreed to partake in the questionnaire's experimentation. In stage two, we selected medical staff in Poland and Ukraine. In stage three, we conducted the questionnaire in the two countries in the first quarter of 2019. In the absence of the possibility of interviewing all Polish and Ukrainian health professionals, we have

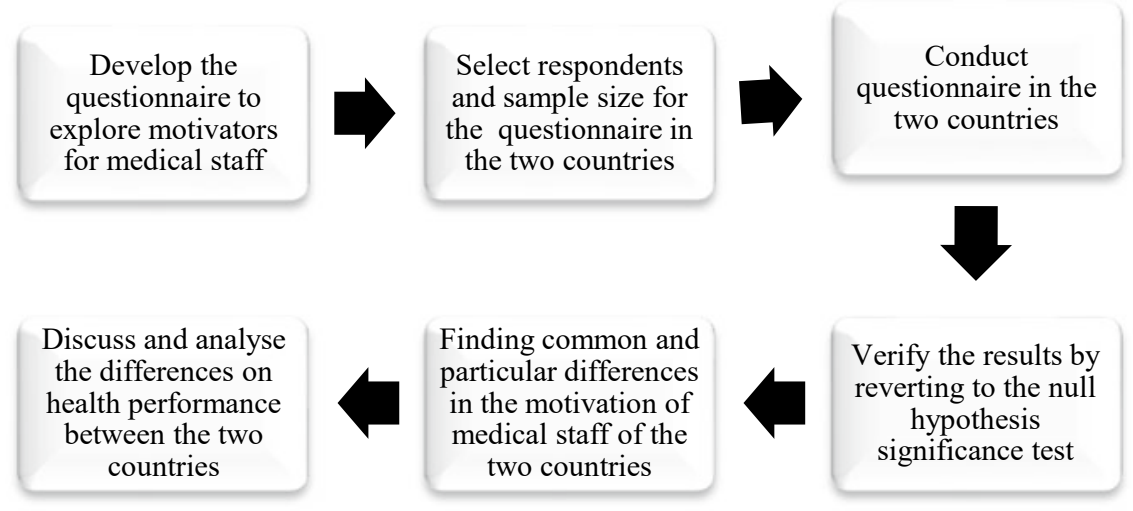

Fig. 8.1 Six-stage scheme of the study 
formed two national samples, which include respondent groups that correspond in composition (i.e. profession, gender and age) to the framework of medical staff in these countries.

We considered three of the main groups of respondents in every country: experienced doctors, nurses and intern doctors. A total of 268 respondents participated in the survey, i.e., 142 respondents in Poland and 126 in Ukraine.

Descriptive statistics for the two national samples are presented in Table 8.1.

In stage four, we verified the results by reverting to the null hypothesis significance test, by using the Kruskal-Wallis test by ranks [40], a non-parametric method for testing whether samples originate from the same distribution. In stage five, if the null hypothesis is not confirmed, i.e. $\mathrm{HO}=$ false, an analysis of the differences in motivation between Polish and Ukrainian responses is conducted-testing each motivator. Statistical analysis incorporated the well-known Pearson correlation coefficient [6] with the Chaddock scale [12] as well as one-way analysis of variance (ANOVA) [5, 16]. And finally, in stage six, we discuss these differences in the context of possible positive or negative influences for medical staff motivation in both countries. Using this information, we can recommend healthcare reformers and policymakers the appropriate steps to improve healthcare performance via the assessed motivators.

Table 8.1 Descriptive statistics for national samples of medical staff

\begin{tabular}{|c|c|c|c|c|c|c|}
\hline Country & Variable & Groups & Total & $\operatorname{Mean}^{\dagger}$ & $\operatorname{Median}^{\dagger}$ & Stand. dev. ${ }^{\dagger}$ \\
\hline Poland & Profession & Experienced doctors & 46 & \multirow[t]{3}{*}{20} & \multirow[t]{3}{*}{21} & \multirow[t]{3}{*}{1.5} \\
\hline \multirow[t]{8}{*}{$(n=142)$} & & Nurses & 70 & & & \\
\hline & & Intern doctors & 26 & & & \\
\hline & Gender & Male & 21 & 46 & 43 & 15.6 \\
\hline & & Female & 121 & 43 & 44 & 13.4 \\
\hline & Age & $18-34$ & 28 & \multirow[t]{4}{*}{43} & \multirow[t]{4}{*}{44} & \multirow[t]{4}{*}{1.6} \\
\hline & & $35-44$ & 49 & & & \\
\hline & & $45-54$ & 34 & & & \\
\hline & & $55+$ & 31 & & & \\
\hline Ukraine & Profession & Experienced doctors & 14 & \multirow[t]{3}{*}{17} & \multirow[t]{3}{*}{15} & \multirow[t]{3}{*}{1.2} \\
\hline \multirow[t]{8}{*}{$(n=126)$} & & Nurses & 34 & & & \\
\hline & & Intern doctors & 78 & & & \\
\hline & Gender & Male & 25 & 25 & 23 & 6.7 \\
\hline & & Female & 99 & 25 & 21 & 10.8 \\
\hline & Age & $18-34$ & 108 & \multirow[t]{4}{*}{39} & \multirow[t]{4}{*}{37} & \multirow[t]{4}{*}{1.3} \\
\hline & & $35-44$ & 9 & & & \\
\hline & & $45-54$ & 5 & & & \\
\hline & & $55+$ & 4 & & & \\
\hline
\end{tabular}

\footnotetext{
${ }^{\dagger}$ Profession $=$ based on years of experience, gender and age $=$ based on mean age
} 
The results of this study brought the main findings that may be useful for reforming inefficient healthcare systems, namely:

(1) Working conditions in an inefficient healthcare system are perceived by medical staff much worse than in an efficient one. However, medical staff in an inefficient system can be more optimistic.

(2) Medical staff in efficient and inefficient healthcare systems has different influencing motivators.

(3) There are huge differences in the motivation of medical staff in terms of profession, gender, and age. Hence, to achieve a high-performance healthcare system, this difference must be considered when developing a system of incentives for medical staff.

(4) The number of motivators for experienced doctors and nurses in an inefficient healthcare system is much less than in an efficient one; furthermore, with older age, this difference becomes higher. These findings are probably due to the disappointing fact that medical staff working in a system that has poor conditions lack proper facilities.

(5) Medical staff in an efficient healthcare system is well-motivated by moral, internal and external (i.e., financial) incentives. In an inefficient system, experienced medical staff is motivated mainly by moral incentives, but with older age, the need for social benefits increases especially for female staff.

This study has brought us closer to discovering a possible influence on the motivation of medical staff on the efficiency of healthcare systems [9, 27, 46]. Further research will need to establish the presence (or absence) of correlative means between medical staff motivation and healthcare system efficiency. As with the comparative research from Poland and Ukraine, the identified significant differences in motivation, in terms of efficient versus inefficient system, is refuted leaving the longing sense that such a relationship may be possible. Overall, the research gives us hope that interlinkages can be further established - utilizing the five recommended reform enablers.

\subsection{Conclusion}

In this Chapter we discussed human resources impact, and alternative explanation for barriers and facilitators for implementation of PCC evolving from human resources through the lenses of institutional theory. Managers may support the implementation of PCC, but their motivation would be not only to increase service quality. Quality improvement leaders in hospitals need to be included in the development of these programs through the measure for improving the quality of the work process. One of the barriers to PCC implementation in healthcare is the result of the lack of PCC education. The lack of understanding of person-centred care concept could lead to a lack of motivation for implementation The authors of research in Ukraine and Poland have compiled research to test comparative findings for different motivators of medical staff in countries with a high gap in healthcare efficiency by examining the 
motivation of health professionals in Polish and two Ukrainian hospitals. The results of this study brought the main findings that may be useful for reforming inefficient healthcare systems.

Acknowledgements 1 This publication is based upon work from COST Action "European Network for cost containment and improved quality of health care-CostCares" (CA15222), supported by COST (European Cooperation in Science and Technology)

COST (European Cooperation in Science and Technology) is a funding agency for research and innovation networks. Our Actions help connect research initiatives across Europe and enable scientists to grow their ideas by sharing them with their peers. This boosts their research, career and innovation.

https://www.cost.eu

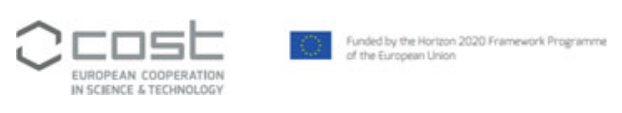

Acknowledgements 2 This work was supported by the National Science Centre Poland (Grant Number: 2015/17/B/HS4/02747).

\section{References}

1. Abbott, A.: The System of Professions: An Essay on the Division of Labor. University of Chicago Press (1988)

2. Aduo-Adjei, K., et al.: The impact of motivation on the work performance of health workers (Korle Bu Teaching Hospital): evidence from Ghana. Hosp. Practices Res. 1(2), 47-52 (2016)

3. Afolabi, A., et al.: The effect of organisational factors in motivating healthcare employees: a systematic review. Br. J. Healthc. Manag. 24(12), 603-610 (2018)

4. Alharbi, T.S., et al.: Implementation of Person-centred Care: Management Perspective. JHA 3(3), 107 (2014). https://doi.org/10.5430/jha.v3n3p107

5. Annerstedt, M., et al.: Inducing physiological stress recovery with sounds of nature in a virtual reality forest—Results from a pilot study. Physiol. Behav. 118, 240-250 (2013)

6. Benesty, J., et al.: Pearson correlation coefficient. In: Cohen, I., Huang, Y., Chen, J., Benesty, J. (eds.) Noise Reduction in Speech Processing, Springer, Berlin, Heidelberg, pp. 1-4 (2009)

7. Berghout, M., et al.: Healthcare professionals' views on patient-centered care in hospitals. BHC Health Serv. Res. 15, 385 (2015). https://doi.org/10.1186/s12913-015-1049-z

8. Bolster, D., Manias, E.: Person-centred interactions between nurses and patients during medication activities in an acute hospital setting: Qualitative observation and interview study. Int. J. Nurs. Stud. 47(2), 154-165 (2010). https://doi.org/10.1016/j.ijnurstu.2009.05.021

9. Bortoletto, G., Favaro, D.: Healthcare efficiency across European countries during the recent economic crisis. Economia Pubblica 2019(2), 9-38 (2019)

10. Cantor, V.J.M., Poh, K.L.: Integrated analysis of healthcare efficiency: a systematic review. J. Med. Syst. 42(1), 1-23 (2018)

11. Cerasoli, C.P., et al.: Intrinsic motivation and extrinsic incentives jointly predict performance: A 40-year meta-analysis. Psychol. Bull. 140(4), 980-1008 (2014)

12. Chaddock, R.E.: Principles and Methods of Statistics. Houghton Mifflin (1925)

13. COST Action (2017). European Network on cost containment and quality in healthcare. MoU, 2017. 
14. Covaleski, M.A., et al.: An institutional theory perspective on the DRG framework, casemix accounting systems and health-care organizations. Acc. Organ. Soc. 18(1), 65-80 (1993). https://doi.org/10.1016/0361-3682(93)90025-2

15. Coulter, A., Oldham, J.: Person-centred care: what is it and how do we get there? Future Hosp. J. 3(2), 114-116 (2016)

16. Cuevas, A., et al.: An ANOVA test for functional data. Comput. Stat. Data Anal. 47(1), 111-122 (2004)

17. Currie, G., et al.: HR practices and knowledge brokering by hybrid middle managers in hospital settings: the influence of professional hierarchy. Hum. Resour. Manage. 54(5), 793-812 (2015). https://doi.org/10.1002/hrm.21709

18. Del Rocío Moreno-Enguix et al.: Analysis and determination the efficiency of the European health systems. Int. J. Health Plann. Manage. 33(1), 136-154 (2018)

19. Dellenborg, L., et al.: Factors that may promote the learning of person-centred care: an ethnographic study of an implementation programme for healthcare professionals in a medical emergency ward in Sweden. Adv. Health Sci. Educ. 24, 353-381 (2019). https://doi.org/10.1007/ s10459-018-09869-y

20. DiMaggio, P., Powell, W.W.: The iron cage revisited: collective rationality and institutional isomorphism in organizational fields. Am. Sociol. Rev. 48(2), 147-160 (1983)

21. Dussault, G., Dubois, C.A.: Human resources for health policies: a critical component in health policies. Hum. Resour. Health 1(1), 1 (2003)

22. Dwibedi, L.: Impact of employees motivation on organizational performance. Acad. Voices Multi. J. 7, 24-30 (2017)

23. Ekman, et al.: Person-centred care-Ready for Prime Time. Eur. J. Cardiovasc. Nurs. 10(4), iii-iii (2011). https://doi.org/10.1016/j.ejcnurse.2011.06.008

24. European Commission (2017) Tools and methodologies to assess integrated care in europe. Report by the expert group on health systems performance assessment. Luxembourg: Publications Office of the European Union

25. Freidson E (1988) Profession of Medicine: A Study of the Sociology of Applied Knowledge. University of Chicago Press

26. Freidson E (2001) Professionalism, The Third Logic: On the Practice of Knowledge. University of Chicago press

27. Goncharuk, A.G.: Socioeconomic Criteria of Healthcare Efficiency: An International Comparison. J. Appl. Manag. Investments 6(2), 89-95 (2017)

28. Goncharuk, A.G.: Exploring a motivation of medical staff. Int. J. Health Plann. Manage. 33(4), 1013-1023 (2018)

29. Goncharuk, A.G., et al.: Motivators for medical staff with a high gap in healthcare efficiency: comparative research from Poland and Ukraine. Int. J. Health Plann. Manage. 35(6), 1314-1334 (2020)

30. Goodrick, E., Reay, T.: Constellations of institutional logics: changes in the professional work of pharmacists. Work. Occup. 38(3), 372-416 (2011). https://doi.org/10.1177/073088841140 6824

31. Greiner, A.C., Elisa ,K.: Health Professions Education. A Bridge to Quality, Institute of Medicine. Washingtone, National Academic Press (2003)

32. Greenwood, R., et al.: Institutional complexity and organizational responses. Acad. Manag. Ann. 5(1), 317-371 (2011)

33. Harris, C., e al,: Human resource management and performance in healthcare organisations. J. Health Organ. Manag. 21, 448-459 (2007)

34. Hazarika, I.: Health workforce governance: key to the delivery of people-centred care. Int. J. Healthc. Manage. (2019). https://doi.org/10.1080/20479700.2019.1647380

35. Health Foundation: Person-centred care made simple: What everyone should know about person-centred care. (2014). https://www.health.org.uk/publications/person-centredcare-made-simple

36. Hughes, R.G.: Patient Safety and Quality: An Evidence-Based Handbook for Nurses. Rockville: Agency for Healthcare Research and Quality (US) (2008) 
37. Institute of Medicine (IOM): Crossing the Quality Chasm: A New Health System for the 21st Century. National Academy Press, Washington, D.C (2001)

38. Jones, C., Livne-Tarandach, R.: Designing a frame: rhetorical strategies of architects. J. Organ. Behav. 29(8), 1075-1099 (2008)

39. Kabene, S.M., et al.: The importance of human resources management in healthcare: a global context. Hum. Res. Health 4(20), (2006). https://doi.org/10.1186/1478-4491-4-20

40. Kruskal, W.H., Wallis, W.A.: Use of ranks in one-criterion variance analysis. J. Am. Stat. Assoc. 47(260), 583-621 (1952)

41. Kuhlmann, E., et al.: "A manager in the minds of doctors:" a comparison of new modes of control in European hospitals. BMC Health Serv. Res. 13(1), 1 (2013). https://doi.org/10.1186/ 1472-6963-13-246

42. Kujawska, J.: Efficiency of Healthcare Systems in European Countries-the DEA Network Approach. Metody Ilościowe w Badaniach Ekonomicznych 19(1), 60-70 (2018)

43. Lewandowski RA (2014) Cost control of medical care in public hospitals-a comparative analysis. Int. J. Contemp. Manage. 13(1)

44. Lewandowski, R.A., Sułkowska, J.: Levels of hybridity in healthcare sector. In: Teczke, J., Buła, P. (eds.) Management in the time of networks, cross-cultural activities and flexible organizations, pp. 147-162. Cracow University of Economics, Cracow (2017)

45. Lewandowski, R.A., Sułkowski, Ł.: New Public Management and Hybridity in Healthcare: The Solution or the Problem? In: Savignon AB, Gnan L, Hinna A, Monteduro F (eds) Hybridity in the Governance and Delivery of Public Services. Emerald Publishing Limited, pp. 141-166 (2018)

46. Lo Storto, C., Goncharuk, A.G.: Efficiency vs effectiveness: a benchmarking study on European healthcare systems. Econ. Sociol. 10(3), 102-115 (2017)

47. Lounsbury, M.: Institutional transformation and status mobility: the professionalization of the field of finance. Acad. Manag. J. 45(1), 255-266 (2002)

48. Mannion, R., Davies, H.T.: Payment for performance in health care. BMJ 336(7639), 306-308 (2008)

49. Manzoor, Q.A.: Impact of employees' motivation on organizational effectiveness. Bus. Manage. Strategy 3(1), 1-12 (2012)

50. May, C., Finch, T.: Implementing, embedding, and integrating practices: an outline of normalization process theory. Sociology 43(3), 535-554 (2009). https://doi.org/10.1177/003803850 9103208

51. McCormack, B.: Person-centredness in gerontological nursing: an overview of the literature. J. Clin. Nurs. 13(s1), 31-38 (2004). https://doi.org/10.1111/j.1365-2702.2004.00924.x

52. McKay, K.A., Narasimhan, S.: Bridging the gap between doctors and nurses. JNEP 2(4), (2012). https://doi.org/10.5430/jnep.v2n4p52

53. McPherson, C.M., Sauder, M.: Logics in action: managing institutional complexity in a drug court. Adm. Sci. Q. 58(2), 165-196 (2013)

54. Meyer, J.W., Rowan, B.: Institutionalized organizations: formal structure as myth and ceremony. Am. J. Sociol. 83(2), 340-363 (1977)

55. Mintzberg, H., Waters, J.A.: Of strategies, deliberate and emergent. Strateg. Manag. J. 6(3), 257-272 (1985)

56. Moore, L., et al.: Barriers and facilitators to the implementation of person-centred care in different healthcare contexts. Scand. J. Caring Sci. 31(4), 662-673 (2017). https://doi.org/10. $1111 / \mathrm{scs} .12376$

57. Nadeem, M., et al.: Impact of employee motivation on employee performance (A case study of Private firms: Multan District, Pakistan). Int. Lett. Soc. Humanistic Sci. 36, 51-58 (2014)

58. Naldemirci, Ö., et al.: Deliberate and emergent strategies for implementing person-centred care: a qualitative interview study with researchers, professionals and patients. BMC Health Serv. Res. 17(1):527 (2017). https://doi.org/10.1186/s12913-017-2470-2

59. Patient Safety: Danish society for patient safety. (2020). https://patientsikkerhed.dk/content/ uploads/2016/08/dsfppersoncentredcare.pdf 
60. Platis, C., et al.: Relation between job satisfaction and job performance in healthcare services. Procedia Soc. Behav. Sci. 175(1), 480-487 (2015)

61. Ratanawongsa, N., et al.: What motivates physicians throughout their careers in medicine? Compr. Ther. 32(4), 210-217 (2006)

62. Reay, T., Hinings, C.R.: Managing the rivalry of competing institutional logics. Organ. Stud. 30(6), 629-652 (2009). https://doi.org/10.1177/0170840609104803

63. Reay, T., Hinings, C.R.: The Recomposition of an Organizational Field: Health Care in Alberta. Organ. Stud. 26(3), 351-384 (2005). https://doi.org/10.1177/0170840605050872

64. Rigoli, F., Dussault, G.: The interface between health sector reform and human resources in health. Hum. Resour. Health 1(1), 9 (2003)

65. Samuel, S., et al.: Monetized medicine: from the physical to the fiscal. Acc. Organ. Soc. 30(3), 249-278 (2005)

66. Santana, MJ., et al.: How to practice person-centred care: a conceptual framework. Health Expect. 00, 1-12 (2017). https://doi.org/10.1111/hex.12640

67. Scott, W.R., et al.: Institutional Change and Healthcare Organizations: From Professional Dominance to Managed Care. University of Chicago Press, Chicago (2000)

68. Shahzadi, I., et al.: Impact of employee motivation on employee performance. Eur. J. Bus. Manage. 6(23), 159-166 (2014)

69. Silva-Ayçaguer, et al.: The null hypothesis significance test in health sciences research (19952006): statistical analysis and interpretation. BMC Med. Res. Methodol. 10(1), 44 (2010)

70. Smaldone, P., Vainieri, M.: Motivating health professionals through control mechanisms: a review of empirical evidence. J. Hosp. Admin. 5(3), 75 (2016)

71. Suddaby, R., Greenwood, R.: Rhetorical strategies of legitimacy. Adm. Sci. Q. 50(1), 35-67 (2005)

72. Svensson, R.: The interplay between doctors and nurses-a negotiated order perspective. Sociol. Health Illn. 18(3), 379-398 (1996)

73. Swarna Nantha, Y.: Intrinsic motivation: the case for healthcare systems in Malaysia and globally. Hum. Resour. Dev. Int. 20(1), 68-78 (2017)

74. Thornton, P.H., Ocasio, W.: Institutional logics and the historical contingency of power in organizations: Executive succession in the higher education publishing industry, 1958-19901. Am. J. Sociol. 105(3), 801-843 (1999)

75. Thornton, P.H., Ocasio, W.: Institutional logics. In: Greenwood, R., Oliver, C., Suddaby, R., Sahlin-Andersson, K. (eds.) The Sage Handbook of Organizational Institutionalism. pp. 99-128 (2008)

76. Thornton, P.H., Ocasio, W., Lounsbury, M.: The Institutional Logics Perspective: A New Approach to Culture, Structure, and Process. Oxford University Press on Demand (2012)

77. Valentjn, P., et al.: Understanding integrated care: a comprehensive conceptual framework based on the integrative functions of primary care. Int. J. Integr. Care (2013). URN:NBN:NL:UI:10$1-114415$

Open Access This chapter is licensed under the terms of the Creative Commons Attribution 4.0 International License (http://creativecommons.org/licenses/by/4.0/), which permits use, sharing, adaptation, distribution and reproduction in any medium or format, as long as you give appropriate credit to the original author(s) and the source, provide a link to the Creative Commons license and indicate if changes were made.

The images or other third party material in this chapter are included in the chapter's Creative Commons license, unless indicated otherwise in a credit line to the material. If material is not included in the chapter's Creative Commons license and your intended use is not permitted by statutory regulation or exceeds the permitted use, you will need to obtain permission directly from the copyright holder. 